\title{
EREBEA
}

Revista de Humanidades

y Ciencias Sociales

Núм. 7 (2017), pp. 179-193

ISSN: 0214-0691

\section{“¿ALGUNA VEZ HABÉIS VISTO UN ALMA?" ATEÍSMO POPULAR Y ESCEPTICISMO RELIGIOSO EN VENECIA DURANTE la Edad Moderna}

\author{
Federico Barbierato \\ Università di Verona
}

RESUMEN

Desde hace tiempo, la historia de la incredulidad religiosa, el ateísmo y la libertad de pensamiento han constituido esencialmente una historia intelectual, basada en el estudio de libros impresos y manuscritos clandestinos. Asimismo, se ha focalizado en autores, la más de las veces en estudios de carácter biográfico $y$, en ocasiones, ha pretendido reconstruir grupos y redes de pensadores que pertenecían a una cultura básicamente escrita. El objetivo del presente artículo es mostrar, a través del análisis de un estudio particular como el de la Venecia de los siglos XVI y XVII, cómo el fenómeno del disenso religioso, incluso el de matriz radical como el ateísmo o la irreligiosidad, ha formado una dimensión compleja en la historia cultural y social de la Edad moderna, no anclándose rígida y necesariamente en grupos sociales $o$ intelectuales sino expandiéndose a sectores mucho más amplios.

\section{Palabras Clave}

Venecia; edad moderna; disenso; ateísmo; "libertinismo".

Fecha de recepción: 8 de sept. de 2017

Fecha de aceptación: 11 de nov. de 2017

\section{Abstract}

For some time, the history of religious incredulity, atheism and freedom of thought, has been primarily an intellectual history, based on the study of printed books and clandestine manuscripts. Furthermore this one has been focused on authors, mainly biographies, and sometimes this History has tried to define groups and network of thinkers who belonged to a written culture. This article attempts to show, through the particular study of Venice in XVIth and XVIIth centuries, that religious dissent, even this one that contains a radical germ like atheism or irreligiousness, has created a complex dimension in Early modern cultural and social history. And all this may be done without been unyielding and necessarily anchored in social and intellectual groups but by enlarging this reading of the history to wider sectors.

\section{KeYwords}

Venice; Early modern period; dissent; atheism; "libertinism". 

Es sabido que Venecia constituye una realidad muy particular respecto a muchos otros contextos italianos. En muchos sentidos, la ciudad representaba un lugar de libertad por los márgenes de la independencia que habían sido capaces de lograr con respecto a Roma. La política jurisdiccionalista veneciana había creado, de hecho, las condiciones para una relativa autonomía de las decisiones pontificias. Así y todo, la actividad inquisitorial había debido subordinarla a una serie de vínculos que habían limitado su capacidad de iniciativa. Por otra parte, Venecia era una ciudad difícilmente controlable: demasiadas personas y demasiado diferentes, confinadas en un espacio que parecía realizado a propósito para garantizar los intercambios, los contactos o las contaminaciones culturales ${ }^{2}$.

Ya a partir del siglo XVI, la ciudad no parecía para nada "en sintonía con la atmósfera de la contrarreforma" ${ }^{3}$. No es casualidad que, precisamente en Venecia, se hubiese desarrollado el Colloquium heptapolomeres de Jean Bodin, casi remarcando la percepción de la laguna como un espacio libre y abierto. Un par de siglos más tarde, se había afirmado completamente la idea de un lugar que permitía el libre pensamiento. A comienzos del siglo XVIII, una broma francesa describía bien el estado de ánimo escéptico de la zona lagunar. Decía aproximadamente que, en Francia, cuando se llevaba la eucaristía a un enfermo, eran pocos los que acompañaban la ostia. En Francia, Dios estaba entre amigos, a diferencia de Venecia. Aquí "temiéndose algo, cuando sale, lleva una escolta para defenderse" Obviamente, no sé si en Francia las escoltas eran inútiles, y, por otra parte, no creo tampoco en el empleo en términos historiográficos de una broma parecida. En cualquier caso, incluso en la exageración típica de la polémica, dicha broma expresaba la idea generalizada de una ciudad empapada de palabras y comportamientos marcados por un escepticismo general. Palabras que formaron discursos, convicciones y debates entre personas quizás poco preparadas en el ámbito del

2 Sobre estos temas, el primer punto de referencia es G. Spini, Ricerca dei Libertini. La teoría dell'impostura delle religioni nel Seicento italiano. Firenze: La Nuova Italia, 1983. Véase también F. Barbierato, The Inquisitor in the Hat Shop: Inquisition, Forbidden Books and Unbelief in Early Modern Venice. Farnham: Ashgate, 2012.

3 G. Cozzi, Stato e Chiesa: un confronto secolare, in Venezia barocca. Conflitti di uomini e idee nella crisi del Seicento veneziano. Venezia: Il Cardo, p. 267.

4 Archivio di Stato di Venezia (en lo sucesivo, ASVe), Inquisitori di Stato, b. 627, declaración de G[iacomo] Roselli del 26 de septiembre de 1707. 
conocimiento teológico, pero bastante propensas a confrontarse con un modelo de referencia social afirmado: el del filósofo o el del ingenioso.

Durante el siglo XVII, estos discursos parecen articularse en torno a un núcleo fuerte, que se puede definir fácilmente como "libertino". No es que dichos discursos hubiesen estado ausentes con anterioridad: lo que había cambiado durante estos ańos era el radicalismo de los discursos, que no encontraban un vínculo inmediato a corrientes heréticas concretas. En ellos, confluían fuentes, reflexiones e informaciones personales encarnadas en individuos especialmente dispuestos a hacerlos públicos en los lugares de discusión.

Se trataba de una especie de materialismo o irreligiosidad popular, como ha sido definida en el cual, sin embargo, el adjetivo popular debería definir más bien al acontecimiento en sí que al ámbito social. De hecho, se ha discutido mucho sobre las características de una heterodoxia similar, y parece indudable que la incredulidad y la irreligiosidad "populares" podían también emerger en ausencia de una fuerte influencia "aprendida": cada uno podía, a fin de cuentas, desarrollar una experiencia directa que le hiciese darse cuenta de la escasa inclinación de Dios a los asuntos humanos. Incluso no era necesario leer las obras de Lucrecio para confirmar su posición.

Sin embargo, es al menos evidente, a partir de la documentación (procesos inquisitoriales, fuentes narrativas, informes de viaje, documentos producidos por cuerpos policiales, etc.) que en el siglo XVI se habían establecido y convertido en dominio público un conjunto de ideas, palabras y discursos heterodoxos y escépticos que comprendían diferentes niveles y grados de procesamiento intelectual. Retomando el estudio fundamental de Carlo Ginzburg, el problema, en un contexto urbano como Venecia, no era tanto tener que lidiar con un Menocchio, como el ruido - más o menos bajo - de cientos de individuos que compartían con Menocchio sus características en cuanto aptitud e ingenio ${ }^{5}$.

Obviamente, es difícil encontrar un denominador común en los discursos que tienen que ver con una multitud de referencias irreligiosas o incrédulas. Una etiqueta trivial, pero quizás no del todo incorrecta, podría ser la de "libertinismo". Tampoco con anterioridad había faltado una corriente de este tipo en la sociedad veneciana. No obstante, a lo largo del siglo XVII parece haber aumentado la carga del radicalismo en proposiciones no adscribibles a determinadas corrientes heréticas. Desde este punto de vista, los mismos inquisidores luchaban para definir un enemigo difícil de alcanzar, formado por recorridos individuales y reelaboraciones continuas en lugar de adhesiones a "Ecclesie" o grupos con un credo común. Les era imposible - tanto para ellos como para los historiadoresestablecer distinciones claras. Más aún cuando no se trataba, en realidad, de cues-

5 Referencia obviamente a C. Ginzburg, Il formaggio e i vermi. Il cosmo di un mugnaio del '500. Torino: Einaudi, 1976, p. 11. 
tiones completamente nuevas. La incredulidad del siglo XVII atraía a corrientes que se han extendido durante siglos y se han combinado de nuevo de una manera más o menos original. Existían el averroísmo, el aristotelismo heterodoxo, el maquiavelismo y elementos de la tradición "politique" que formaban parte de una zona gris donde se cruzaban el antitrinitarismo, las recepciones de la Reforma y la Razón de Estado. Según lo escrito por Adriano Prosperi, "manifestaciones de incredulidad o de materialismo popular [...] siempre habían existido y continuaban existiendo" ${ }^{\prime 6}$, en un proceso de continua contaminación con una estructura de la cultura italiana de largo período, aquella "minoritaria pero resistente tradición de humanismo radical" que, finalmente, confluiría con las filosofías de origen francés ${ }^{7}$. Lo que cambiaba respecto al pasado era la percepción de un rol social completamente nuevo, despreocupado en la medida de lo posible de la vigilancia de las instituciones de la Contrarreforma. Una disidencia para nada peligrosa, pero sí ruidosa, que no sólo ponía en tela de juicio los dogmas y los artículos de fe establecidos, sino que atacaba a las religiones. Todas las religiones eran percibidas como hábiles invenciones que los "poderosos" habían creado para mantener a los pueblos bajo control.

De esta situación no se podía salir: ningún tipo de reivindicación social o política se encuentra en estos discursos. Lo que se buscaba era mostrar que se podía revelar el juego ${ }^{8}$. El resultado fue una forma particular de materialismo o irreligión popular capaz de atravesar a toda la sociedad. Por lo tanto, el concepto de "popular" debe entenderse como indicativo a nivel de difusión más que como una característica calificadora. Tales formas de materialismo o irreligión pudieron afirmarse incluso sin una fuerte influencia "conocedora": en este sentido, la intersección de diferentes tradiciones podría ser un punto de partida hacia heterodoxias más estructuradas, respaldadas por discusiones, aprendizajes y lecturas.

Así, durante todo el siglo XVII, una serie de ideas y discursos escépticos, extremadamente peligrosos para el Santo Oficio, se extendieron en todos los sectores de la sociedad. Su objetivo era contrarrestar sistemas de pensamiento y fragmentos de discurso capaces de afectar a diferentes niveles, además de estar sometidos y creados por elaboraciones intelectuales muy diferenciadas. Como se ha mencio-

6 A. Prosperi, Dare l'anima. Storia di un infanticidio. Torino: Einaudi, 2005, p. 229.

7 V. Frajese, Profezia e machiavellismo. Il giovane Campanella. Roma: Carocci, 2002, pp. 10-11.

8 No era una particularidad veneciana. Según Jonathan Israel, después de 1650 todo, sin importar su trascendencia, fue cuestionado y reemplazado sobre la base del análisis filosófico: J.I. Israel, Radical Enlightenment. Philosophy and the Making of Modernity. 1650-1750. Oxford: Oxford University Press, 2002, p. 3. Incluso en Venecia parecía haber madurado "el tiempo de la heterodoxia, de todos los heterodoxos; de los ingobernables, de los rebeldes, [...] que pululaban en la sombra, esperando sólo la señal de liberación; de científicos que se niegan a aceptar la tradición sin controlarla; de jansenistas, que quieren resucitar su llama nunca extinguida; de los piadosos de cada especie; de los exégetas; de los filósofos": P. Hazard, La crisi della coscienza europea. Torino: Einaudi, 1946, p. 102. 
nado, el ruido de fondo de una ciudad habitada por cientos de Menocchi, cada uno en contacto diario con los demás y con todas las formas de enriquecimiento que la ciudad ofrecía, creó de hecho, una situación imposible de controlar para las fuerzas inquisitoriales. Una ciudad donde la alteridad estaba siempre presente y donde las propuestas religiosas alternativas, ciertamente, no faltaban: judíos, turcos, evangélicos, griegos, etc., podían reunirse en cualquier lugar, hablar entonces de religión o religiones y concluir que aquella en la cual se había creído no era, quizás, la mejor. Por lo tanto, toda una serie de temas y asuntos en los que se habían visto comprometidos círculos identificados con el libertinismo erudito, circulaban ahora ya no sólo entre la aristocracia y en una proporción "grande", sino también más generalmente entre el clero - regular y secular - y entre los niveles populares de la ciudad.

El rasgo característico de esta circulación, por supuesto, está constituido por la variedad con la que fueron acogidos, reelaborados y transmitidos. De hecho, el proceso de elaboración individual se desarrollaba a partir de las formulaciones, en lugar de reconstruir las estructuras de los discursos. En su mayoría, se partía de un sentimiento de insatisfacción con su estado, o de la observación del comportamiento injusto de las jerarquías eclesiásticas que imponían códigos prescriptivos percibidos como opresivos, especialmente en el ámbito sexual. Tenían que ver con concepciones materialistas más que libertinas - ¡cómo creer que fuese posible salvarse si la naturaleza humana era corrupta? ¿Qué destino tenía el alma después de la muerte? Y entonces, ¿existía un alma? - o también se relacionaban con temas que interesaban a los "politiques", ofreciendo variaciones singulares en la doctrina de la implantación política de las religiones.

Estos fueron temas bastante homogéneos, que tomaron forma sobre la base de un vocabulario limitado y de herramientas conceptuales que no siempre fueron de primera elección. Sin embargo, contaban con descartes entre elaboraciones individuales, de modo que las formas del discurso heterodoxo terminaron siendo casi infinitas. De ahí la atención que se debe prestar a las formas de expresión. Ejemplo de ello es el caso de Teodoro Stricher, un experto en leyes que, en torno 1660, recorrió la ciudad tratando de convencer a sus interlocutores de que Dios era completamente indiferente al hombre. El alma, en su opinión, era corpórea y, por lo tanto, mortal. Si hubiese habido un concilio, habría estado muy contento de asistir: podría haber expuesto sus ideas en un foro adecuado. En ausencia de éste, se contentaba con el público de las tiendas: notarios, traperos y trabajadores. Ciertamente, el lenguaje tenía que adaptarse. Ante todo, era necesario mencionar a las autoridades en las que se basaba la visión, razón por la que insistía en que los "doctores", antes de él, habían afirmado la mortalidad del alma. Pero para entenderse mejor, se recurría a la cotidianeidad: en aquella Cuaresma había pocos 
peces en el mercado. Era un signo inequívoco de que Dios "quería que se comiese la carne, así decía el Evangelio"”.

El ejemplo es trivial y elegido al azar entre otros muchos. Existía un mecanismo generalizado: vincular la declaración a datos concretos la volvía autoevidente, fácil de pronunciar y muy eficaz durante las discusiones públicas. Por este motivo, para quienes escuchaban, resultaba fácil apropiarse e intercambiar formulaciones de este tipo. Ciertamente, el público no permanecía pasivo, todos aportaban y volvían a poner en circulación recomposiciones de fragmentos de discurso construidos, a menudo, por acumulación. No era demasiado importante que las combinaciones funcionaran perfectamente en estas construcciones "artesanales". El fin último era la producción y exhibición de fórmulas simples, elásticas y de impacto. ¿Cómo medir la existencia misma de Dios, si no mediante la experiencia diaria de privaciones e insatisfacciones? ¿Qué credibilidad tenía un cuerpo eclesiástico cuya primera preocupación no era la devoción? ¿Cómo creer en las religiones cuando eran tantas y tan diferentes, y todas afirmaban ser únicas y verdaderas? Si realmente se tenía que pensar en un más allá, entonces era, sin duda, un lugar en donde había intercambios, pagos, compromisos y protecciones, de acuerdo con una visión enraizada en la experiencia de la vida. No se hacía referencia a las alternativas confesionales: era una heterodoxia centrada en el individuo y en la lectura que cada uno podía dar de su propia condición.

El materialismo que le siguió no era cosa nueva. Era simplemente más ruidoso que en el pasado. Según Nicolò Rompiasio, capaz de atraer la atención del Santo Oficio en 1722, no había ninguna Providencia y daba una demostración práctica de ello "tocándose su bolsillo en el que tenía algo de dinero con la mano" y añadiendo: "Esto es la providencia. En cambio, id a Cristo a haceros dar limosna, rogadle y oradle, y después él os dará una patada en la cara". Y en cuanto al alma: "Diantres, ¿qué alma? ¿Alguna vez habéis visto un alma? Cuando estás muerto, no hay nada más". La gracia de Dios llegaba cuando "se tiene la barriga llena". Además del Paraíso, simple invención de los sacerdotes para creer en un sistema de premios y castigos que engañaba, y, además, los constreñía en cuanto a comportamientos y creencias. En el fondo era mejor así: si hubiera existido, el paraíso habría sido un lugar peligroso porque "los que suben allí [...] caen abajo, y caen en cien mil deseos, y si Cristo está en el paraíso, allí se queda”. No es que la posición fuera rígida con respecto a la otra vida: a veces la negaba por completo, otras la reinterpretaba: “¿qué paraíso? Los paraísos son cuatro, es decir, el que está en el cielo, la iglesia, la taberna y la mujer, y estos paraísos son contrarios entre sí”. Las religiones eran todas inventos, pero el cristianismo era sin duda el peor. Peor que

9 ASVe, Sant'Uffizio, b. 117, fascículo Teodoro Stricher, testimonio espontáneo de Francesco Priuli del 10 de abril de 1674 . 
el judaísmo y el islam: "id junto un cristiano a pedir que os ayude e id junto a un judío, veréis que os ayudará el judío y no el cristiano" 10 .

Como ya se mencionó, no era una cuestión de solidez en los argumentos. Y no era cosa nueva. Corría el año 1576 cuando un tornero, Matthew Winston, había sostenido públicamente que, teniendo que creer en algo irreal, prefería más creer que tenía dinero en el bolsillo y no Dios ${ }^{11}$. Ni siquiera era una cuestión de género: Orsola Ciuran, la esposa de un trapero, declaraba en 1646 que "el alma es una porquería, y los que no están bien en el cuerpo tampoco están bien en el alma. ¿Qué es el infierno? No se ha encontrado ninguno que haya venido aquí a decirlo" 12 .

El mecanismo de repetición pública de este tipo de discurso tenía un primer efecto: reafirmaba en sus propias convicciones a quien lo pronunciaba y dotaba a los individuos de un repertorio de ideas capaz de proporcionarles una caracterización social. La expresión de una posición heterodoxa, en otros términos, acababa convirtiéndose en una identidad: la de "ingenioso", "virtuoso", "filósofo", etc. Era el individuo, o el sentido de la individualidad, el que prevalecía sobre la adhesión a las propuestas de fe compartida. Hacia 1650 el dominico Fray Tommaso Onorio circulaba diciendo que las religiones habían inventado al diablo, así como a la Trinidad. Cada uno podía salvarse a sí mismo creyendo lo que quería y, si la Iglesia decía que no, era sólo porque el gobierno de los "papistas" era tiránico. Una prueba clara de esto era el hecho de que a los religiosos se les impedía tener relaciones sexuales mientras habrían podido y, sobre todo, habrían debido tenerlas. Incluso el prior le había escuchado decir esas cosas. Lo había escuchado a menudo pero no se sorprendió: Fray Tommaso era básicamente un buen hombre religioso que cumplía con su deber. Era uno "que decía cosas de ese tipo para demostrar que era un tipo despierto y, como se suele decir, un ingenioso"13. Algo completamente externo, estético.

10 ASVe, Sant'Uffizio, b. 139, fascículo Nicolò Rompiasio, testimonio espontáneo de Matteo Scaglioni del 9 de julio de 1722, cc. 1v-2v y compuesto de Nicolò del 19 de enero de 1723, c. 30r.

11 ASVe, Sant'Uffizio, b. 40, fascículo Marcantonio de Simon y Francesco Paluelo, denuncia del 1 de mayo de 1576.

12 ASVe, Sant'Uffizio, b. 103, fascículo Ludovico Fugarola ..., testimonio espontáneo de Antonia Sgambozza del 5 de junio de 1646. Sobre el carácter imaginario de las penas infernales véase R. Klein, La forma e l'intelligibile. Scritti sul Rinascimento e l'arte moderna. Torino: Einaudi, 1975 y, más en general, D.P. Walker, The Decline of Hell. Seventeenth Century Discussion of Eternal Torment. Chicago: University of Chicago Press, 1964.

13 ASVe, Sant'Uffizio, b. 106, fascículo Caterina Tordana ..., dossier Fray Tommaso Onorio, declaración de fray Ludovico da Murano, prior del convento de San Pietro di Murano, del 6 de julio de 1651. Se trataba de una posición un poco común para todas las polémicas y la literatura antilibertina. Según Filippo Maria Bonini, por "lujuria de ingenio" los ingeniosos terminaban por renegar de la religión, naufragando "en el mar tempestuoso de filosofías fluctuantes". Era el "querer pasar por cerebros singulares" para poner en peligro el alma: F.M. Bonini, L'ateista convinto dalle sole ragioni. Venezia: Pezzana, 1665, pp. 20, 36. 
Uno se volvía "despierto" o "ingenioso" con los discursos, con la capacidad de sorprender, expresando escepticismo extremo, airado o irónico. Los «filósofos» eran un modelo alcanzable: cuestionaban la religión y sus artificios, y observaban los vínculos con la lógica del poder. Con esto, no pretendían meter mano en el orden social. Era absolutamente esencial que éste permaneciera como estaba: el poder no podía ser manejado por ignorantes y "monos". La religión era un medio de control social necesario, pero era necesario mostrar que se estaba entre los que comprendían que las cosas funcionaban así.

Tomemos las palabras pronunciadas por el abad Francisco Muselani en 1682: "los imbéciles creen que existe el purgatorio y la casa del diablo, pero no los

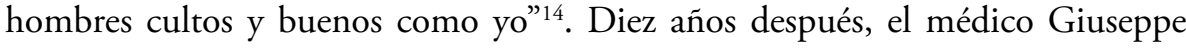
Rossi señalaba, proponiendo una variante del sueño de Maquiavelo que, incluso si hubiese un paraíso, el infierno sería preferible con diferencia. Mejor "ir a donde han ido muchos emperadores infieles, como Tiberio, Nerón y otros, que no ir al paraíso para estar acompañados de cuatro pescadores"15. El paraíso era algo para "niños", según le había enseñado a Giacomo Stecchini, un aprendiz de pintor, su maestro, del que aprendió no sólo el oficio. Tanto es así, que Giacomo pronto sugeriría una variante: "el paraíso era el paraíso de los imbéciles" ${ }^{16}$. Al mismo tiempo, el canciller pretorio de Mestre, Daniele Alberti, explicaba a amigos y sirvientes "que las almas pasan de un cuerpo a otro, pero estaba hablando de las almas de los hombres, de los personajes grandes y virtuosos, diciendo también, al mismo tiempo, que al paraíso van sólo los imbéciles y los ignorantes, y que al infierno van sólo los hombres grandes y virtuosos, y que él quería irse al infierno, entre los hombres grandes y virtuosos"17.

Si los eruditos negaban los dogmas, Dios, en el Más Allá, para acercarse a ellos, necesitaba afirmar las mismas cosas, quizás yendo por caminos propios $\mathrm{y}$, como se ha dicho anteriormente, materiales. Pero era cuestión de ser como ellos. Alrededor de 1670, el marqués Francesco Maria Santinelli y el doctor Vincenzo Pezzi intentaron persuadir al comerciante Francesco Giusto de "no creer en los sacramentos, diciendo que los buenos filósofos no creen en otra cosa que no sea la naturaleza" ${ }^{18}$. Era necesario aprovechar, como hacían los filósofos, la verdad

14 ASVe, Sant'Uffizio, b. 123, fascículo Francesco Muselani, testimonio espontáneo de don Giuseppe Mauccio del 11 de agosto de 1682, c. 5v.

15 ASVe, Sant'Uffizio, b. 126, fascículoTobia Haselberg, escrito sin fecha, marcada A, presentado por Domenico Paterno, en la sesión del 22 de mayo de 1692, c. 2v.

16 ASVe, Sant'Uffizio, b. 135, fascículo Giacomo Stecchini, testimonio espontáneo de Bernardo Testi, del 21 de mayo de 1711 e interrogado por Giacomo el 23 de febrero de 1712.

17 ASVe, Sant'Uffizio, b. 138, fascículo Margherita Mazzer ..., proceso contra Daniele Alberti, declaración de Michelangelo Bellotto del 6 de febrero de 1721 .

18 ASVe, Sant'Uffizio, b. 119, fascículoFederico Gualdi, escrito de Francesco Giusto, presentado el 21 de abril de 1676, c. 1 r. 
oculta tras la religión. Y la verdad era simple porque no había nada más que la naturaleza y el hombre. Todo lo demás era una invención y los "verdaderos filósofos" sabían que las cosas eran materiales y corporales. En abril de 1699, el fiscal Paolo Marchesi Vedova podía presentar frente al librero Domenico Lovisa "la opinión de la mayoría de los grandes hombres, de que, muerto el cuerpo, se ha muerto también el alma"19.

Pero si el modelo estaba representado por "filósofos" y "grandes hombres", y si se quería que los demás supiesen que eran como ellos, ¿tenía sentido esconder sus opiniones? Era evidente que, queriendo parecerse a ellos, era necesario hacer pública la irregularidad de su sistema filosófico y la libertad de la mente. Poco antes, el Theophrastus redivivus había dotado de argumentos filosóficos la afirmación de que los verdaderos eruditos eran los únicos capaces de observar la realidad, analizarla y destapar los engaños de la religión ${ }^{20}$. "Personas grandes y letradas, que han sido muchas" habían enseñado a la mencionada Orsola Ciuran que el alma era mortal, que los sacramentos eran inútiles y que el infierno, obviamente, no existía. Se lo habían dicho muchos, "casi todo el mundo". Orsola le había confesado a la amiga Maddalena, y "una y otra habían empezado a negarse a recibir los santísimos sacramentos" ${ }^{21}$. No querían parecer tontas. A quien le regañaba devotamente por haber dicho que el alma era mortal, que las religiones eran una invención y que el Más Allá no existía, el vicentino Grando di Grandi, en 1692, respondía que "se necesita decir algo para no parecer un mono"22.

Había, entonces, doctos y "monos", "virtuosos" e "imbéciles". Los "filósofos" eran pocos y el resto no cuestionaba seriamente la tesis de que la política, el conocimiento, la cultura, las lecturas y la incredulidad debían mantenerse en círculos restringidos: sería ruinoso para la sociedad si se hubiesen vuelto patrimonio generalizado. Este era el caso de los secretos de la política. Se creía comúnmente que eran áreas separadas y restringidas. No obstante, al menos desde mediados del siglo XVII, el número de aquellos a quienes se les permitió unirse a ese grupo restringido aumentó. Existían, de hecho, cosas de las que otros no habrían tenido que hablar, áreas de conocimiento limitado, ocultas y reservadas. Como señala Arlette Farge a propósito del siglo XVIII parisino:

19 ASVe, Sant'Uffizio, b. 129, fascículoMargherita Brancaleoni ..., procedimiento contra Paolo Marchesi Vedova, testimonio espontáneo de Domenico Lovisa del 30 de abril de 1699.

20 Véase Theophrastus redivivus, editado por G. Canziani, G. Paganini. Firenze: La Nuova Italia, 1981, 2 vol.

21 ASVe, Sant'Uffizio, b. 103, fascículo Ludovico Fugarola ..., procedimiento contra Orsola Ciuran, testimonio espontáneo de Antonia Sgambozza del 5 de junio de 1646.

22 ASVe, Sant'Uffizio, b. 127, fascículo Grando de Grandi, testimonio espontáneo de Zanetta di Grandi del 3 de septiembre de 1692. 
Chacun s'autorise de dire et de penser; dans cette permission que chacun se donne à lui-même, ponctuée par une répression qui ne la fait jamais faiblir, s'invente non pas tant de nouvelles formes de subversionne qu'un affinement des capacités cognitives et réflexives. Loriginalité de cette période tient plus aux formes prises pas la discussion et la critique quau contenu même de la critique ${ }^{23}$.

Todo estaba organizado para ocultar la realidad y popularizar los pensamientos del vulgo con fantasmas de castigos divinos. ¿De qué otra manera explicar la prohibición de los libros? Obviamente estaban "prohibidos por tener oculta la verdad y mantener al pueblo sometido" 24 . Pero, como explicaba Michelangelo Fardella en 1689, tales prohibiciones debían concernir solo a los "imbéciles"25. Los "virtuosos", eran silenciosamente autorizados a leer lo que querían. Del mismo modo se les permitía romper los códigos prescriptivos y morales: en 1736 el doctor Andrea Pisani - y es sólo uno de los muchos casos posibles - proponía de nuevo su estereotipo del filósofo y el virtuoso en relación no sólo con la heterodoxia religiosa, sino también con la libertad sexual: "ir a las putas no era un pecado" y quien, como los turcos, podía legalmente tener una multitud de mujeres, era ciertamente afortunado. Era una libertad en que, sin embargo, en otros contextos religiosos, se recortaban los principios y, si él lo hubiese estado, habría hecho exactamente lo mismo. No era tanto una cuestión de matrimonio, dado que casarse "era cosa de imbéciles": "solo los ignorantes y los idiotas se casan y ... los filósofos y los hombres doctos, como era él, filósofo, no se casan nunca, pero mantienen más mujeres para sus propios placeres, porque esto no era pecado". No había nada de malo en eso porque "en la ley de la naturaleza" los hombres podían tener todas las mujeres que querían, ya que habían sido creadas "para el disfrute y placer de los hombres"26.

Disputas y discusiones tenían reglas precisas y constituían una especie de suspensión de la comunicación normal, una especie de territorio libre donde el gusto de medirse con los demás conducía a abandonar la cautela y la apariencia. En 1679, el sacerdote Pietro Mariani había expuesto, ante una audiencia numerosa y participante, una rica colección de doctrinas incrédulas. Llamado a rendir

23 A. Farge, Dire et mal dire. L'opinion publique au 18e siècle. Paris: Seuil, 1992, p. 265.

24 ASVe, Sant'Uffizio, b. 132, proceso " del 5 marzo ", declaración de Antonio Partenio del 8 de abril de 1705 , cc. 8 r bis.

25 ASVe, Sant'Uffizio, b. 125, fascículo fray Michelangelo Fardella, declaración del benedictino Gerardo Mutio del 16 de junio de 1689.

26 ASVe, Sant'Uffizio, b. 142, fascículo Antonio Pisani, testimonio espontáneo de Angelo Mazzon el 21 de agosto de 1736. Sobre la posición hostil al matrimonio véase Spini, Ricerca dei libertini, p. 165. 
cuentas, se justificó argumentando que "estaba fuera de mí porque estábamos conversando" 27 .

Probablemente la de Mariani no era solo una estrategia defensiva. En muchos casos, la disputa tuvo que ser sentida como un ejercicio intelectual que permitía ir más allá del conformismo. Fray Enrico da Venezia, en 1651, había presenciado, ciertamente, la exhibición de todo el arsenal libertino por su hermano Tommaso Onorio. Pero no le había dado mucha importancia, "pensando que diría esto por disputa, y no de verdad" 28 . He llegado a creerlo: una gran parte de los testigos y acusados que habían estado tratando con el Santo Oficio tenían en verdad una línea de defensa creíble, y no hay razón para dudar del hecho de que muchos tenían que ser pasatiempos o ejercicios retóricos que no implicaban necesariamente la adhesión a las proposiciones expresadas: "Se puede discutir incluso si Dios existe - fue la opinión de fray Elia Borghi en 1687 - porque la mejor manera de sacar la luz es rodearla de oscuridad" 29 .

Se trataba casi de un espectáculo que, de alguna manera, era deudor de la disputa teológica pública medieval. Pero aquí los actores en escena no eran grandes teólogos; eran voluntariosos amantes del patchwork filosófico en busca de certezas y distracciones: en 1661 Antonio Stella, después de haber tenido la oportunidad de escuchar al médico Troilo Lanzetta negar la muerte del alma, había invitado repetidamente al padre Giovan Francesco Priuli a tratar con el médico "porque es filósofo" ${ }^{30}$. Antonio discutía mucho con el médico, y no siempre le entendía lo suficiente, pero aquel poco le parecía que no era demasiado ortodoxo. No obstante, "me dije a mí mismo que había muchos otros prudentes y sabios que conocían el estilo de vida de este médico", y, por tanto, permanecía pasmado ${ }^{31}$.

Una vez que ese alto conocimiento se convertía en corriente de discusión, no había ninguna razón para considerarlo sagrado. Era algo para usar y, en algún nivel de elaboración de su pensamiento heterodoxo, el público común ya no era suficiente. Eran necesarios interlocutores a la altura, adversarios adecuados. Lo había deseado también el molinero Menocchio, declarando abiertamente que habría querido confrontarse con las autoridades al respecto de las propias opiniones sobre la $\mathrm{fe}^{32}$. No era el único: entre los siglos XVI y XVIII, hay muchas declara-

27 ASVe, Sant'Uffizio, b. 122, fascículo don Pietro Mariani, interrogatorio del 16 de julio de 1680.

28 ASVe, Sant'Uffizio, b. 106, fascículo Caterina Tordana ..., procedimiento contra fray Tommaso Onorio, declaración de fray Enrico da Venezia del 15 de julio de 1651.

29 ASVe, Sant'Uffizio, b. 125, fascículo Fray Elia Borghi, interrogatorio del 9 de diciembre de 1687.

30ASVe, Sant'Uffizio, b. 110, fascículo Fray Fontanarosa, dosier Troilo Lanzetta, escrito de Fray Giovan Francesco Priuli presentado el 28 de octubre de 1661.

31 Ivi, declaración de Antonio Stella del 29 de noviembre de 1661.

32 Ginzburg, Il formaggio e i vermi, p. 11. 
ciones de este tipo en los procesos inquisitoriales. A principios del siglo XVIII, Giovanni Bresciani había atravesado una crisis escéptica. Había madurado una serie de pensamientos que lo habían convencido. Pero estaba cansado de hablar "para si". Entonces, como le dijo al inquisidor:

A menudo he tenido la tentación de encontrar a algún hombre culto para discutir, creyendo que nadie sería capaz de persuadirme y quitarme mis dudas, así que [...] anhelaba que hubiera hombres más cultos en el mundo porque hacía tiempo que deseaba hablar sobre estas cosas, pero [...] en otras ocasiones he expresado con otros las dudas que ya he mencionado para hablar y poner en problemas ${ }^{33}$.

Todo había partido de una prohibición trivial: Giovanni había perdido su trabajo y tenía problemas financieros. Él siempre había sido considerado un hombre de fe, moralmente correcto. ¿Por qué ahora lo abandonaba Dios y ayudaba a tanta gente mala? ¿Cómo podía Dios permitir ciertas injusticias? ¿Por qué permitió que Adán agarrase la manzana y que Judas traicionara a Jesús? ¿ No los castigaba conscientemente a la condenación eterna? La justicia de Dios era una quimera, por lo que Giovanni había decidido ir a Ginebra "y allí predicar contra de la fe de Cristo". Probablemente los ginebrinos no habrían mostrado una gran apertura. Giovanni tuvo que darse cuenta de por qué permaneció en territorio católico ${ }^{34}$. De hecho, se había lanzado ingresando como novicio en los agustinos de Treviso. El acto de fe no había sido recompensado: a causa de una disputa con el padre maestro, abandonó el hábito sin abonar la suma pagada en el momento de la entrada. Esta era la enésima injusticia, unida a los pensamientos que ya le se le habían presentado en el pasado. Por tanto, la transición de la crítica en las comparaciones de los religiosos a la irreligiosidad fue rápida. Los agustinos, afirmó, eran pícaros. Y fue más allá, especificando que las tomas de hábito se habían introducido para comerle el dinero a las personas.

Desde este discurso y desde este pensamiento, he pasado con la mente para reflexionar sobre las dispensas, que se obtienen desde Roma, y reflexionando que, para obtener dispensas e indultos se necesita gastar algo de dinero. Empecé dentro de mí a dudar de que se debería creer al Papa, porque él estaba haciendo todo por interés, y que, en consecuencia, incluso nuestra ley no era buena. Me acerqué

33 ASVe, Sant'Uffizio, b. 136, fascículo Giovanni Bresciani y Antonio Legrenzi, testimonio espontáneo de Giovanni Bresciani del 26 de marzo de 1709.

34 ASVe, Sant'Uffizio, b. 136, proceso contra Giovanni Bresciani y Antonio Legrenzi, testimonio espontáneo de Giovanni Bresciani del 26 de marzo de 1709. 
y empecé a preguntarme si el misterio de la encarnación era falso, porque -me dije- María era una mujer como cualquier otra, no era posible que Dios hubiese enviado a su hijo a encarnar en el vientre de una mujer similar a las otras y que habían nacido, también ella, en este mundo. Además, pensé que era falsa la resurrección de los muertos, o más bien que la muerte de los hombres fuese similar a la muerte de los animales, por lo tanto, negaba que nuestra alma fuese racional, diciendo que, en cambio, era solamente sensible, y creía que después de esta vida no había nada más. Discurriendo sobre la manzana prohibida de Adán, dentro de mí, y reflejando que cuando Dios había hecho esta prohibición ya sabía que Adán no lo habría obedecido, llegué a la conclusión de que, si Dios lo sabía, y, no obstante, lo había prohibido igualmente, era una señal de que Dios quería y causaba nuestro mal. También empecé a aborrecer todas las cosas eclesiásticas, es decir, me decía que, de todos los rituales que se hacen en las iglesias, no había ninguno que fuese bueno, y así continué en esta falsa creencia casi por espacio de tres años, y la he expresado en dos formas: una, diciendo yo mismo, con mi boca, lo anterior sobre estas herejías; y, la otra, haciendo referencia, en los debates, a estas opiniones, afirmando que habían sido pronunciadas por herejes, discutiendo entre nosotros con Bastian Nelli, cirujano de mi maestro, del que estaba iluminado; y satisfecho en el afrontamiento de estas dudas que he propuesto, aún si yo no se las refería como ideas creídas por mí, sino pareciendo hacer esto solo por curiosidad de entendimiento y de saber.

No se había detenido. Había venido a invocar al diablo, en quien también creía intermitentemente. Él le había donado el alma a cambio de algún favor. Pero cuando no apareció ni funcionaron las evocaciones de que fue persuadido, se convenció de que no existía ninguna realidad ultraterrena. Había comenzado a recorrer las iglesias para reírse de quien realizaba gestos de devoción. Afortunadamente, había conocido a Antonio Legrenzi, un hijo de dieciocho años de un comerciante de paños que se había revelado a él, "uniforme de sentimiento". Cuando se encontraban:

Uno a otro nos animábamos a no creer en nada, es decir, que no hay infierno ni purgatorio, ni paraíso, ni verdadero papa, ni Dios, ni sacramentos, ni la Santísima Virgen; y nos decíamos el uno al otro hablando de la Santísima Virgen: que se vaya a hilar, que le haría mejor irse a hilar, y un día en particular, no recuerdo ni en qué ańo, ni que estación, ni qué lugar, este Legrenzi, al ver un crucifijo pin- 
tado, dirigido a mí me dijo sonriendo y golpeándolo: "mira, mira, dicen que es Cristo. Qué cara de Judas que tiene”, y lo aplaudí y le di la razón.

Habían continuado cultivando su propia incredulidad, recorriendo las iglesias juntos, por el gusto de ridiculizar a los participantes del rito. Cuando el sacerdote

alzaba la ostia, decían a la vez: "levantan al Señor, mira allí, que está el Señor, mira a los que adoran al Señor"; y luego se reían ${ }^{35}$.

Había un fuerte componente de voluntad de no creer en aquel darse ánimo para perseverar en la incredulidad, probablemente común a la de muchos otros venecianos de la época, sólo que Giovanni era un alma atormentada y había terminado por presentarse de frente al inquisidor. También esta vez, sin embargo, las sindéresis que sentía condujeron espontáneamente a Giovanni frente al inquisidor en 1713. Un par de meses más tarde también lo seguiría Legrenzi ${ }^{36}$. Ambos, como en muchos otros casos similares, abjuraron y el Santo Oficio decidió no ir más allá. Había obtenido su victoria en una guerra que no podía ganar. de 1714 . 
